\title{
Synthesis and NMR study of N-heterocyclic Carbenes (NHC) Precursors Derived from Troger's Base
}

\author{
ERIC MUSENGIMANA and CLAVER FATAKANWA \\ Department of Chemistry, National University of Rwanda, Faculty of Science, \\ P.O. Box 117 Butare, Rwanda. \\ *Corresponding author E-mail: emusengimana @ nur.ac.rw \\ http://dx.doi.org/10.13005/ojc/290426
}

(Received: October 28, 2013; Accepted: December 04, 2013)

\begin{abstract}
Since the discovery of olefin metathesis reactions, various catalysts have been developed but those based on Ruthenium and N-heterocyclic carbenes (NHC) ligands are particularly more efficient. Herein, we report a synthesis of NHC precursors derived from the Tröger's base and its analogues which can be used in the synthesis of the new kind of metathesis catalysts. The NHC derived from the Tröger's base present a particular chirality that could affect stereoselectivity of catalysis, and the form "V" of these ligands implies that the aromatic substituents point totally outside the coordination sphere of the metal, where would be no steric hindrance unlike what happens with the usual NHC.
\end{abstract}

Key words: NHC (N-heterocyclic carbenes), Tröger's base, Perhalogenated adducts, thioureas adducts.

\section{INTRODUCTION}

Since their discovery in 1931, increasing attention is still paid to the olefination metathesis reactions ${ }^{1}$. These reactions correspond to the redistribution of hydrocarbon backbone of the molecules in which carbon-carbon double bonds are rearranged ${ }^{2}$. They have multiple and varied applications in organic synthesis, in perfume industry, in biology, in pharmaceutical chemistry, in polymers and petrochemicals industry. Therefore, considerable progress has been made for the development of olefin metathesis in organic synthesis ${ }^{3,4}$. Numerous studies have been devoted to the development of efficient metathesis catalysts based on ruthenium and $\mathrm{N}$-heterocyclic carbenes $(\mathrm{NHC})$ ligands ${ }^{5-10}$. The NHC are stable derivatives of divalent carbon. Since their discovery by Arduengo in $1991^{11}$, they are increasingly used as ligands in organometallic chemistry. These electron-rich and sterically hindered compounds exert a beneficial influence on the activity of the metal complexes in which they are incorporated ${ }^{5}$. Because of their structural diversity and the strength of their connections with most metals, they lead to robust and selective active species that can be used under mild conditions. They have already given rise to a wide range of catalytic systems and their development is still far from 
complete ${ }^{12}$. Among the hundreds of $\mathrm{NHC}$ available at present, the most used are imidazole derivatives [IMes:1,3-bis(2,4,6-trimethylphenyl)-imidazol-2ylidene and SIMes:1,3-bis(2,4,6-trmethylphenyl)imidazolin-2-ylidene] especially in many metal complexes for olefin metathesis.

The Tröger's base has been synthesized in 1887 by Julius Tröger, but its structure was elucidated 38 years later by Vladimir Prelog and confirmed by X-ray diffraction in $1986^{13}$.

In the last thirty years, considerable progress has been made for the development of olefin metathesis reactions in organic synthesis ${ }^{3,4}$, 14 and numerous studies have been devoted to the development of efficient metathesis catalysts based on ruthenium and $\mathrm{NHC}$ ligands ${ }^{6,14}$. However, no work has been reported to the synthesis of carbenes derived from Tröger's base or their use as ligands in organometallic catalysis. The purpose we set for this study was to synthesize carbene precursors (perhalogenated adducts and thioureas) derived from the Tröger's base and to investigate their conversion into carbenes or into ruthenium complexes.

\section{EXPERIMENTAL}

Solvents used were of technical grade and commercial reagents were purchased from Acros, Sigma-Adrich, ABCR, TCl or Apollo scientific and used as received unless stated otherwise. THF was freshly distilled from sodium with benzophenone under an argon atmosphere. ${ }^{1} \mathrm{H}$ NMR was recorded on a Bruker-300 MHz, APT, COSY, HSQC, and $\mathrm{HMBC}$ were recorded on a Bruker-500 $\mathrm{MHz}$ spectrometer. Chemical shifts are reported relative to $\mathrm{CDCl}_{3}(7.26,77.16 \mathrm{ppm})$. Spectral features were designed as follows: $\mathrm{s}=$ singlet, $\mathrm{d}=$ doublet, $\mathrm{t}=$ triplet, $\mathrm{q}=$ quartet, $\mathrm{m}=$ multiplet. Column chromatography was carried out on silica gel (ROCC 60, 40-63 $1 / 4 \mathrm{~m})$. TLC analyses were performed on commercial aluminum plates bearing a $0.25 \mathrm{~mm}$ layer of Merck Silica gel $60 \mathrm{~F}_{254}$.

Tröger 's base and its analogues (1a-d): -2,8-dimethyl- $6 H, 12 H-5,11$-methanodibenzo[b ,f][1,5]diazocine, -2,8-dimethoxy- $6 H, 12 H-5,11$ methanodibenzo[b, $f][1,5]$ diazocine, -2,8-dichloro$6 H, 12 H-5,11-$ methanodibenzo[b,f][1,5]diazocine,
$6 \mathrm{H}, 12 \mathrm{H}-5,11$-methanodibenzo [b,f][1,5]diazocine, were synthesized according to the methods described in the litterature ${ }^{13,15-17}$. The removal of methylene bridge to the above Tröger's base leading to the corresponding diazocines (2a-d): -2,8-Dimethyl$5,6,11,12$-tetrahydrodibenzo [b, f] [1,5] diazocine,2,8-Dimethoxy-5,6,11,12-tetrahydrodibenzo [b, f] [1,5] diazocine, -2,8-dichloro-5,6,11,12-tetrahydrodibenzo $[b, f][1,5]$ diazocine, $-5,6,11,12$-tetrahydrodibenzo [b, f] $[1,5]$ diazocine were synthesized according to the methods described in the literature ${ }^{18}$.

\section{Synthesis of $\mathrm{C}_{6} \mathrm{~F}_{5}$-adduct of Tröger's base bearing the chloro, methyl and methoxy groups (3a-3c)}

In a GPC bottle, glacial acetic acid (1 $\mathrm{mL})$; 2,8-Dichloro-5,6,11,12-tetrahydrodibenzo [b, f] $[1,5]$ diazocine $(1 \mathrm{mmol})$ or 2,8-Dimethyl-5,6,11,12tetrahydrodibenzo $[\mathrm{b}, \mathrm{f}][1,5]$ diazocine $(1 \mathrm{mmol})$ or 2,8-Dimethoxy-5,6,11,12-tetrahydrodibenzo [b, f] $[1,5]$ diazocine $(1 \mathrm{mmol})$ and $\mathrm{C}_{6} \mathrm{~F}_{5} \mathrm{CHO}(1.5 \mathrm{mmol})$ were introduced. The reaction mixture was stirred at room temperature until a precipitate appears. It was filtered and washed with cold methanol $\left(-20^{\circ}\right.$ C). The resulting white solids were extracted with dichloromethane. After evaporation under reduced pressure, the solid was analyzed by NMR.

\section{Methyl derivative (3a)}

5h, white solid, yield: $0.32 \mathrm{~g} ; 76 \% ;{ }^{1} \mathrm{H}$ NMR $\left(400 \mathrm{MHz}, \mathrm{CDCl}_{3}\right) \delta 7.1-6.9(\mathrm{~m}, 2 \mathrm{H}), 6.8-6.7(\mathrm{~m}, 2 \mathrm{H})$, $6.5(\mathrm{~s}, 1 \mathrm{H}), 6.2(\mathrm{~s}, 1 \mathrm{H}), 5.5(\mathrm{~s}, 1 \mathrm{H}), 4.75\left(\mathrm{~d},{ }^{2} J_{\mathrm{HH}}=\right.$ $16.6 \mathrm{~Hz}, 1 \mathrm{H}), 4.4\left(\mathrm{~d},{ }^{2} \mathrm{~J}_{\mathrm{HH}}=16.6 \mathrm{~Hz}, 1 \mathrm{H}\right), 4.2\left(\mathrm{~d},{ }^{2} J_{\mathrm{HH}}\right.$ $=16 \mathrm{~Hz}, 1 \mathrm{H}), 4.15\left(\mathrm{~d},{ }^{2} J_{\mathrm{HH}}=16.2 \mathrm{~Hz}, 1 \mathrm{H}\right), 2.1(\mathrm{~s}$, $6 \mathrm{H})$.

\section{Methoxy derivative (3b)}

48h, white solid, yield: $0.35 \mathrm{~g} ; 78 \% ;{ }^{1} \mathrm{H}$ NMR $\left(400 \mathrm{MHz}, \mathrm{CDCl}_{3}\right) \delta$ 7.2-7.0 (m, 2H), 6.8-6.7 (m, 2H), $6.47(\mathrm{~s}, 1 \mathrm{H}), 6.33(\mathrm{~s}, 1 \mathrm{H}), 5.65(\mathrm{~s}, 1 \mathrm{H}), 4.85\left(\mathrm{~d},{ }^{2} \mathrm{~J}_{\mathrm{HH}}\right.$ $=16.7 \mathrm{~Hz}, 1 \mathrm{H}), 4.31\left(\mathrm{~d},{ }^{2} \mathrm{~J}_{\mathrm{HH}}=16.7 \mathrm{~Hz}, 1 \mathrm{H}\right), 4.15$ $\left(\mathrm{d},{ }^{2} J_{\mathrm{HH}}=17.3 \mathrm{~Hz}, 1 \mathrm{H}\right), 4.05\left(\mathrm{~d},{ }^{2} J_{\mathrm{HH}}=17.4 \mathrm{~Hz}, 1 \mathrm{H}\right)$, $3.70(\mathrm{~s}, 6 \mathrm{H})$.

\section{Chloro derivative (3c)}

5 min, white solid, yield: $0.2 \mathrm{~g}, 45 \%,{ }^{1} \mathrm{H}$ NMR $\left(400 \mathrm{MHz}, \mathrm{CDCl}_{3}\right) \delta 7.15-6.68(\mathrm{~m}, 8 \mathrm{H}), 5.55(\mathrm{~s}, 1 \mathrm{H})$, $4.77\left(\mathrm{~d},{ }^{2} \mathrm{~J}_{\mathrm{HH}}=16.8 \mathrm{~Hz}, 1 \mathrm{H}\right), 4.23\left(\mathrm{~d},{ }^{2} J_{\mathrm{HH}}=16.7 \mathrm{~Hz}\right.$, $1 \mathrm{H}), 4.10\left(\mathrm{~d},{ }^{2} J_{\mathrm{HH}}=17.4 \mathrm{~Hz}, 1 \mathrm{H}\right), 3.97\left(\mathrm{~d},{ }^{2} J_{\mathrm{HH}}=17.4\right.$ $\mathrm{Hz}, 1 \mathrm{H})$. 
Synthesis of $\mathrm{C}_{6} \mathrm{~F}_{5}$-adduct of the unsubstituted Tröger's base (3d)

In a GPC bottle, glacial acetic acid $(1 \mathrm{~mL})$; 5,6,11,12-tetrahydrodibenzo [b, f] [1,5] diazocine (1 mmol); p-toluene sulfonic acid $(2-3 \mathrm{~g})$ and $\mathrm{C}_{6} \mathrm{~F}_{5} \mathrm{CHO}(1.5 \mathrm{mmol})$ were introduced. The mixture was allowed to stir for a week at room temperature. The reaction mixture was extracted with chloroform $(10 \mathrm{~mL})$ and washed with a saturated solution of $\mathrm{NaHCO}_{3}(20 \mathrm{~mL} \times 3)$. The organic phase was dried with $\mathrm{MgSO}_{4}$, filtered and concentrated. The orangebrown oil obtained crystallized rapidly. These crystals were washed with cold isopropanol and filtered.

Yield: $0.12 \mathrm{~g}, 32 \%,{ }^{1} \mathrm{H}$ NMR $(400 \mathrm{MHz}$, $\left.\mathrm{CDCl}_{3}\right) \delta 7.25-6.78(\mathrm{~m}, 8 \mathrm{H}), 5.70(\mathrm{~s}, 1 \mathrm{H}), 4.92(\mathrm{~d}$, $\left.{ }^{2} J_{\mathrm{HH}}=16.6 \mathrm{~Hz}, 1 \mathrm{H}\right), 4.42\left(\mathrm{~d},{ }^{2} J_{\mathrm{HH}}=16.6 \mathrm{~Hz}, 1 \mathrm{H}\right)$, 4.19 (q, 2H).

Synthesis of chloroform adduct of Tröger's base unsubstituted or bearing chloro group (4c-4d)

In a GPC bottle, chloral (2 mmol); glacial acetic $(1 \mathrm{~mL})$ acid and 5,6,11,12-tetrahydrodibenzo $[b, f][1,5]$ diazocine $(0.5 \mathrm{mmol})$ or 2,8-Dichloro$5,6,11,12$-tetrahydrodibenzo [b, f] [1,5] diazocine $(0.5 \mathrm{mmol})$ were introduced. After $16 \mathrm{~h}$ of stirring at room temperature, the precipitate was formed and filtered through a Pasteur pipette containing a cotton wool and celite. After washing with cold methanol $\left(-18^{\circ} \mathrm{C}\right)$ the resulting solid was extracted with dichloromethane. The latter was evaporated after and the solid has been analyzed by NMR.

\section{Chloro derivative (4c)}

white powder, yield: $0.02 \mathrm{~g}, 34.31 \%,{ }^{1} \mathrm{H}$ NMR $\left(400 \mathrm{MHz} \mathrm{CDCl}_{3}\right) \delta$ 7.30-6.78 (m, 6H), 4.86$4.68(\mathrm{~m}, 3 \mathrm{H}), 4.32-4.25\left(\mathrm{~d},{ }^{2} \mathrm{~J}_{\mathrm{HH}}=28 \mathrm{~Hz}, 1 \mathrm{H}\right), 4.14-$ $4.07\left(\mathrm{~d},{ }^{2} J_{\mathrm{HH}}=28 \mathrm{~Hz}, 1 \mathrm{H}\right)$.

\section{Hydrogenated derivative (4d)}

yellow powder, yield: $0.1 \mathrm{~g}, 58.82 \%,{ }^{1} \mathrm{H}$ NMR $\left(400 \mathrm{MHz}, \mathrm{CDCl}_{3}\right) \delta 7.30-6.80(\mathrm{~m}, 8 \mathrm{H}), 4.93-$ $4.72(\mathrm{~m}, 3 \mathrm{H}), 4.42-4.35\left(\mathrm{~d},{ }^{2} \mathrm{~J}_{\mathrm{HH}}=28 \mathrm{~Hz}, 1 \mathrm{H}\right), 4.23-$ $4.16\left(\mathrm{~d},{ }^{2} J_{\mathrm{HH}}=28 \mathrm{~Hz}, 1 \mathrm{H}\right)$.

Synthesis of $\mathrm{C}_{6} \mathrm{~F}_{5}$ adduct of 1,3dimesitylimidazolin-2-ylidene (6a)

In a GPC bottle, N,N'- dimesitylethanediamine $(2 \mathrm{mmol})$ and $\mathrm{C}_{6} \mathrm{~F}_{5} \mathrm{CHO}(3 \mathrm{mmol})$ were introduced. The mixture was crushed with a glass rod and a few drops of glacial acetic acid were added while stirring. After adding glacial acetic acid $(1 \mathrm{~mL})$ a precipitate was formed. Another glacial acetic acid $(1 \mathrm{~mL})$ was added, and the precipitate obtained after filtration was washed with cold isopropanol $\left(-20^{\circ} \mathrm{C}\right)$ and then dried. The product was obtained as a white powder.

Yield: $0.34 \mathrm{~g}, 35 \% .{ }^{1} \mathrm{H}$ NMR $(250 \mathrm{MHz}$, $\left.\mathrm{CDCl}_{3}\right) \delta 6.79(\mathrm{~s}, 4 \mathrm{H}), 6.37(\mathrm{~s}, 1 \mathrm{H}), 3.89(\mathrm{~m}, 2 \mathrm{H})$, $3.51(\mathrm{~m}, 2 \mathrm{H}), 2.51(\mathrm{~s}, 9 \mathrm{H}), 2.20(\mathrm{~s}, 9 \mathrm{H}) \cdot{ }^{13} \mathrm{C} \mathrm{NMR}$ $\left(250 \mathrm{MHz}, \mathrm{CDCl}_{3}\right) \delta 139.07,135.46,130.12,71.56$, 51.04, 20.71.

\section{Synthesis of chloroform adduct of 1,3-} dimesitylimidazolin-2-ylidene (6b)

In a GPC bottle, N, N'-ethylene-dimesityl (2 mmol), glacial acetic acid $(2 \mathrm{~mL})$ and chloral (6 $\mathrm{mmol}$ ) were introduced. After $17 \mathrm{~h}$ of stirring at room temperature, there was formation of a precipitate. The latter has been filtered on a Buchner funnel and washed with isopropanol. The substrate has been washed with a saturated solution of $\mathrm{NaHCO}_{3}(10 \mathrm{~mL}$ x 3 ) and extracted with chloroform. The combined organic layers were dried over $\mathrm{MgSO}_{4}$, filtrated, and concentrated under reduced pressure. The product was obtained as a white powder on which ${ }^{1} \mathrm{H}$ NMR and TGA analyses have been performed.

Yield: 0.3g, 36\%. ${ }^{1} \mathrm{H}$ NMR (250 MHz, $\left.\mathrm{CDCl}_{3}\right)$ $\delta 6.85(\mathrm{~d}, 4 \mathrm{H}), 5.57(\mathrm{~s}, 1 \mathrm{H}), 3.91(\mathrm{~m}, 2 \mathrm{H}), 3.29(\mathrm{~m}$, $2 \mathrm{H}), 2.47$ (s, 6H), 2.45 (s, 6H), 2.25 (s, 6H).

\section{Synthesis of the thiourea from Tröger's base} (7)

In a round bottom flask cooled at 0 。 C, 2,8-Dimethyl-5,6,11,12-tetrahydrodibenzo [b, f] $[1,5]$ diazocine $(5 \mathrm{mmol})$ and $\mathrm{Na}_{2} \mathrm{CO}_{3}(0.795$ $\mathrm{g}, 3.75 \mathrm{mmol}$ ) were introduced. In another flask also cooled at $0{ }^{\circ} \mathrm{C}$, was added THF $(5 \mathrm{~mL})$ and thiophosgene $(6 \mathrm{mmol})$. The solution of the second flask was added to the solution of the first flask and stirred overnight at room temperature. The THF was evaporated and the resulting solid was dissolved in dichloromethane $(50 \mathrm{~mL})$. The organic phase was washed with water (50 mL x 3), dried over $\mathrm{MgSO}_{4}$, filtered and evaporated. The crude product was purified by column chromatography on silica gel with EtOAc:Petroleum Ether (8:2). The yellow solid 
obtained after concentration was analyzed by ${ }^{1} \mathrm{H}$ and ${ }^{13} \mathrm{C}$ NMR.

Yield: $0.65 \mathrm{~g}, 46.4 \%{ }^{1} \mathrm{H}$ NMR $(250 \mathrm{MHz}$, $\left.\mathrm{CDCl}_{3}\right) \delta 7.19-6.81(\mathrm{~m}, 6 \mathrm{H}), 6.11-6.07\left(\mathrm{~d},{ }^{3} \mathrm{~J}_{\mathrm{HH}}=16\right.$ $\mathrm{Hz}, 2 \mathrm{H}), 4.45-4.43\left(\mathrm{~d},{ }^{2} \mathrm{~J}_{\mathrm{HH}}=8 \mathrm{~Hz}, 2 \mathrm{H}\right), 2.18(\mathrm{~s}, 6 \mathrm{H})$, ${ }^{13} \mathrm{C}$ NMR $\left(250 \mathrm{MHz}, \mathrm{CDCl}_{3}\right) \delta 174.73,140.05,139.2$, $131.7,130.93,130.7,127.05,59.99,21.19$.

\section{RESULTS AND DISCUSSION}

Our work started by the synthesis of starting materials. Firstly, Tröger's base and its analogues (1a-d) were synthesized according to the method described in the litterature ${ }^{13,15,18}$. Thereafter, we proceeded on the removal of methylene bridge by using the method of Mahon ${ }^{16}$. This lead to the corresponding diazocines (2a-d) that were used in the synthesis of perhalogenated and thiourea adducts.

\section{Synthesis of perhalogenated adducts of the Tröger's base and its analogues}

The diazocines $(2 a-d)$ were treated with
1.5 equiv. of $\mathrm{C}_{6} \mathrm{~F}_{5} \mathrm{CHO}$, in glacial acetic acid. After a stirring at room temperature for various time according to the diazocine, this formally lead to the insertion of a carbene into the $\mathrm{C}-\mathrm{H}$ bond of $\mathrm{C}_{6} \mathrm{~F}_{5} \mathrm{CHO}$ (schemes 1). Interestingly, the chloro derivative 2c was very reactive and lead to the corresponding carbene 3c just after 5 minutes with a yield of $43 \%$. The carbenes $3 \mathrm{a}$ and $3 \mathrm{~b}$ from methyl and methoxy derivatives were isolated easily with good yields of $76 \%$ and $78 \%$ respectively. However, the unsubstituted derivative $2 \mathrm{~d}$ was less reactive in the conditions of the reaction and p-toluene sulfonic acid (10 equiv.) was added (see experimental procedure). In these last conditions, the corresponding carbene $3 d$ was isolated after one week with a low yield $33 \%$; comparing to other derivatives. Several examples from the literature show that $\mathrm{N}$-heterocyclic carbenes of imidazolin-2-ylidene type can be synthesized by heating such compounds ${ }^{19-20}$. In such reactions, there is a loss of $\mathrm{C}_{6} \mathrm{~F}_{5}$ group and the formation of a free carbene.<smiles>[R]c1ccc2c(c1)CNc1ccc([O+])cc1CNc1ccc(I)cc1C2</smiles><smiles>[R]c1ccc2c(c1)CN1c3ccc([R])cc3C(F)(C2)C1F</smiles>

3a: $R=M e, 5 h, 76 \%$

$3 \mathrm{~b}: \mathrm{R}=\mathrm{MeO}, 48 \mathrm{~h}, 78 \%$

3c: $\mathrm{R}=\mathrm{Cl}, 5 \mathrm{~min}, 43 \%$

3d: $R=H, 1$ week, $33 \%$

\section{Scheme 1. Synthesis of $\mathrm{C}_{6} \mathrm{~F}_{5}$-adduct of the Tröger's base and its analogues}

With these interesting carbenes in hands, we were secondly interested by the synthesis of other carbenes by using $\mathrm{Cl}_{3} \mathrm{CHO}$ (chloral) instead of $\mathrm{C}_{6} \mathrm{~F}_{5} \mathrm{CHO}$ (scheme 2).<smiles>[R]c1ccc2c(c1)CNc1ccc([R])cc1CN2</smiles>

2a-d<smiles>O=CC(Cl)(Cl)Cl</smiles>

4 equiv.<smiles>CC(=O)O</smiles>

$\mathrm{R}$<smiles>[R]c1ccc2c(c1)CC1(C)CN2Cc2cc([R])ccc21</smiles>

$4 a: R=M e,-$ $4 \mathrm{~b}: \mathrm{R}=\mathrm{MeO},-$ 4c: $\mathrm{R}=\mathrm{Cl}, 18 \%$ $4 \mathrm{~d}: \mathrm{R}=\mathrm{H}, 50 \%$

Scheme 2. Synthesis of $\mathrm{Cl}_{3} \mathrm{C}$-adducts of the Tröger's base and its analogues 
The results of these syntheses were pretty random. In fact, after dissolving and mixing all the reagents in the glacial acetic acid, we were expecting that the products precipitate as it was the case for the preceding synthesis; but this was not the case. Surprisingly, no reaction was observed for compounds $4 \mathrm{a}$ and $4 \mathrm{~b}$ after an overnight stirring at room temperature. Impure products were isolated containing chloral for methyl derivative $4 a$. For chlorine derivative $4 \mathrm{c}$ and unsubstituted derivative $4 \mathrm{~d}$ there was no appearance of a precipitate and the reaction mixture was partitioned between chloroform and an aqueous solution of $\mathrm{NaHCO}_{3}$. Evaporation of the organic layers led to oils that crystallized after one night.

\section{Thermolysis tests of perhalogenated adducts of Tröger's base}

It is possible to obtain various complexes of rhodium or ruthenium bearing NHC ligands by a conventional heating a suitable metal precursor with $\mathrm{C}_{6} \mathrm{~F}_{5}$ or chloroform adducts of SIMes ligand ${ }^{17}$. We tried to apply this method to the $\mathrm{C}_{6} \mathrm{~F}_{5}$ adducts of the Tröger's base. A first test was performed using as substrate the complex $\left[\mathrm{RuCl}_{2}\left(\mathrm{PCy}_{3}\right)_{2}\right.$ (2-phenylindenylidene)]. The Grubb's metathesis catalyst of first generation was refluxed in toluene for $24 \mathrm{~h}$ in the presence of $3 \mathrm{a}$ (2 equiv.) (Scheme $3)$. The reaction was monitored by a ${ }^{31} \mathrm{P}-\mathrm{NMR}$ and a gradual appearance of a free $\mathrm{PCy}_{3}$ was observed in the reaction mixture. These observations seemed auspicious, the expected reaction involving the substitution of a phosphine ligand by analogous carbene. However, after purification of the crude by column chromatograph on silica gel, ${ }^{1} \mathrm{H}-\mathrm{NMR}$ and ${ }^{13} \mathrm{C}$ NMR analyses performed on the white solid obtained revealed that we did not isolate the expected product. But it was a mixture of uncharacterized products. It is therefore likely that the peak from the free phosphine observed in ${ }^{31} \mathrm{P}$ NMR came from the decomposition of the starting complex, which did not withstand the applied temperature.

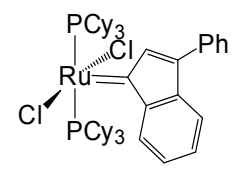<smiles>Cc1ccc2c(c1)CN1CCN2CC1(F)F</smiles>
3a: 2 equiv.

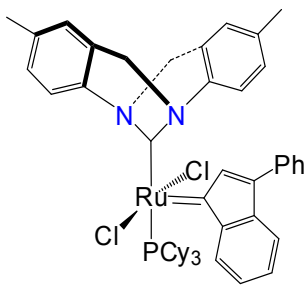

Scheme 3. Thermolysis test of $\mathrm{C}_{6} \mathrm{~F}_{5}$ - adducts of Tröger's base with Ru complex

In parallel, another attempt was carried out by choosing the dimer [RhCl (1,5-cyclooctadiene)] ${ }_{2}$ as a binding site of carbene ligand (Scheme 4) in the same conditions as preceding. In fact, the rhodium complex is an air-stable ruthenium alkylidene species which should better withstand the thermolysis adopted to generate a carbene from the adduct $3 a$.
The subsequent replacement of cyclooctadiene with carbonyl ligand, followed by the determination of vibration frequencies $\mathrm{n} \mathrm{CO}$ with infrared spectroscopy, should also measure the electron-donor power of the carbene derived from the Tröger's base. However, the NMR analysis of the crude of the reaction proved that the starting materials were isolated unchanged; hence no reaction.

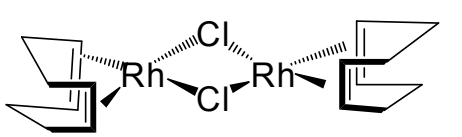<smiles>Cc1ccc2c(c1)CN1CCN2CC1(F)F</smiles>

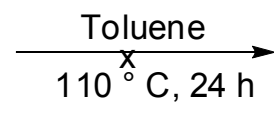<smiles>C=C/C=C(/C)CC</smiles>

3a: 2 equiv.

Scheme 4: Thermolysis test of $\mathrm{C}_{6} \mathrm{~F}_{5}$ - adducts of Tröger's base with Rh complex 
A third attempt to synthesize the free carbene of the Tröger's base or its dimer from the adduct $3 a$ was carried out in a microwave reactor. No metal complex was used in this experiment. The adduct 3a was simply dissolved in dry degassed toluene and the solution was heated in the microwave for half an hour at $200^{\circ} \mathrm{C}$ under pressure. To verify the presence of the carbene, few drops of $\mathrm{CS}_{2}$ were added to the reaction mixture. If a carbene was present in solution, the formation of a colored zwitterion should be observed, but it did not happen. There was no free carbene in solution. A ${ }^{1} \mathrm{H}-\mathrm{NMR}$ spectrum recorded on the crude corresponded to the starting materials.

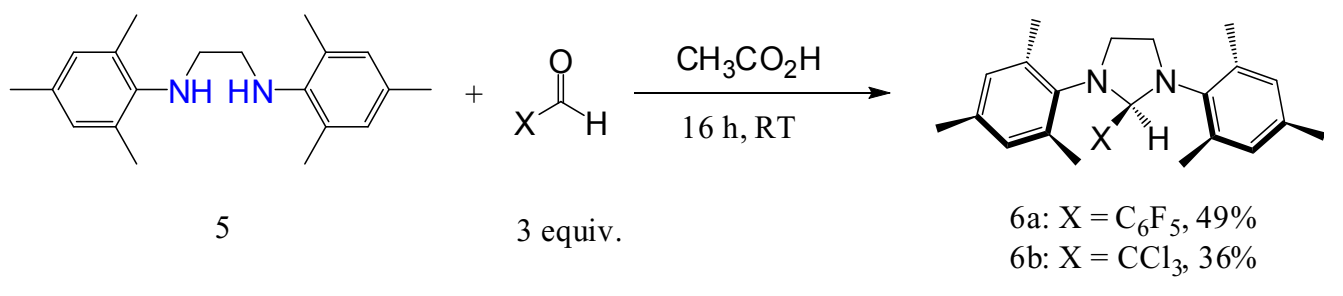

Scheme 5. Synthesis of perhalogenated SIMes adducts

Compounds $6 \mathrm{a}$ and $6 \mathrm{~b}$ have been isolated as white powders with moderate yields; $49 \%, 36 \%$ respectively

A thermogravimetric analysis of perhalogenated adducts of the Tröger's base, 3a, $3 \mathrm{~d}$ and reference compound $6 \mathrm{~b}$ were performed. These measures consisted of heating products in a microbalance and record the mass loss as a function of temperature. From a certain threshold, adducts decompose to form free carbene and expel chloroform or the $\mathrm{C}_{6} \mathrm{~F}_{5} \mathrm{CHO}$. The results of these

\section{Synthesis of perhalogenated SIMes adducts and} thermogravimetric analyzes

In aim to compare the stabilities of the perhalogenated adducts of the Tröger's base with those of classic $\mathrm{N}$-heterocyclic carbenes, we have synthesized $\mathrm{C}_{6} \mathrm{~F}_{5}$ and chloroform adducts of SIMes ligand. The synthesis method used is similar to that followed with the Tröger's base and its analogues, i.e., the secondary diamine ligand $\mathbf{5}$ was stirred at room temperature for $17 \mathrm{~h}$ with 3 equiv. of $\mathrm{C}_{6} \mathrm{~F}_{5} \mathrm{CHO}$ or chloral in the presence of acetic acid (Scheme 5). analyzes showed that the adducts of the Tröger's base remain stable at least up to $200^{\circ} \mathrm{C}$ and the exact nature of the adduct (chloroform or $\mathrm{C}_{6} \mathrm{~F}_{5}$ ) has a very little influence on the decomposition temperature. For example, compounds $3 a$ and $3 d$ both degrade at about $220^{\circ} \mathrm{C}$ (Figure 1). In contrast, compound $6 \mathrm{~b}$ releases chloroform at a very lower temperature, around $145^{\circ} \mathrm{C}$, which explains the difference in reactivity between the two families of carbene precursors.

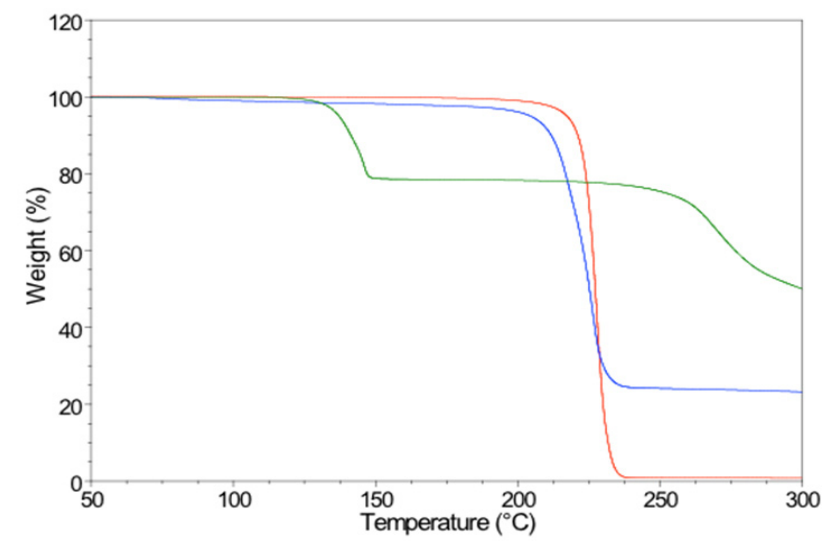

Fig. 1: TGA adducts Tröger-Me. $\mathrm{C}_{6} \mathrm{~F}_{5} \mathrm{H}$ (compound 3a, red curve), Tröger-H. $\mathrm{CHCl}_{3}$ (compound $3 \mathrm{~d}$, blue curve) and $\mathrm{SIMes} . \mathrm{CHCl}_{3}$ (compound $6 \mathrm{~b}$, green curve) 
Synthesis of thiourea of the Tröger's base and its analogues

Thermolysis of perhalogenated adducts of the Tröger's base and its analogues was clearly much more difficult to accomplish than expected. Therefore, we have explored an alternative synthetic route that should lead to the achievement of the desired carbene. This new pathway is based on the use of thiourea as carbene precursors. These compounds can be obtained in one step from compounds $3 a-d$ previously synthesized. They were treated overnight in THF at room temperature with 1.2 equiv. of thiophosgene in the presence of $\mathrm{Na}_{2} \mathrm{CO}_{3}$ $(75 \%)$ to neutralize the hydrochloric acid formed (Scheme 6).<smiles>CCc1ccc2c(c1)CNc1ccc(C)cc1CN2</smiles>

$3 a$

$$
+\quad \mathrm{Cl}_{2} \mathrm{C}=\mathrm{S}
$$

1.2 equiv

$$
\underset{\text { THF, } 16 \text { h, RT }}{\stackrel{\mathrm{Na}_{2} \mathrm{CO}_{3}, 75 \%}{\longrightarrow}}
$$<smiles>Cc1ccc2c(c1)CN1CCN(CC1)c1ccc(C)cc1S2</smiles>

$7,46 \%$

\section{Scheme 6. Synthesis of thiourea of the Tröger's base and its analogue}

After purification by column chromatography on silica gel, the product 7 was isolated as a pure yellow solid with moderate yield of $46 \%$. It was analyzed by NMR. The presence of a characteristic peak of $\mathrm{C}=\mathrm{S}$ between 170 and $180 \mathrm{ppm}$ in ${ }^{13} \mathrm{C}$ NMR spectroscopy revealed that the expected product was formed.

\section{CONCLUSION}

The synthesis of carbenes precursors derived from Tröger's base is feasible. Optimization of experimental conditions will be further investigated to improve yields and purity of isolated products.
With comparative thermogravimetric analysis, we have shown that adducts pentafluorobenzene and chloroform of the Tröger's base are much stable than those derived from a classic NHC. Refluxing in toluene in the presence of a complex of Ru or Rh, and the irradiation at $200^{\circ} \mathrm{C}$ in a microwave reactor haven't allowed the desired thermolysis. The study of an alternative way to achieve the carbene from Tröger's base involving thioureas as an intermediate key should be further investigated. A further study should also be undertaken to investigate the effectiveness of these new catalysts especially in cross-coupling metathesis reactions.

\section{REFERENCES}

1. Schuster M., Blechert S., Angew. Chem. Int. Ed., 36: 2036 (1997).

2. Astruc D., Actualité chimique, 273: 3 (2004).

3. Chauvin Y., Angew. Chem. Int. Ed., 45: 3740 (2006).

4. Grubbs R. H., Angew. Chem. Int. Ed., 45: 3760 (2006).

5. Herrmann W. A., Angew. Chem. Int. Ed., 41: 1290 (2002).

6. Samojlowicz C., Bienik M., Grela K., Chem. Rev., 109: 3708 (2009).

7. Schrock R. R., Chem. Rev., 109: 3211 (2009).

8. Vougioukalakis G. C., Grubbs R. H., Chem.
Rev., 110: 1746 (2010).

9. P. Kumar, Orient. J. Chem., 29(3): 1225-1231 (2013).

10. C.P. Choudhary, S.P. Sharma, C.L. Rai and B.K. Rai, Orient. J. Chem., 29(3): 963-967 (2013).

11. Arduengo III A. J., Harlow R. L., Kline M., J. Am. Chem. Soc., 113: 361 (1991).

12. Hahn F. E., Jahnke M. C., Angew. Chem. Int. Ed., 47: 3122 (2008).

13. Sergeyev S., Helv. Chim. Acta, 92: 415 (2009).

14. Schrock R. R., Angew. Chem. Int. Ed., 45: 3748 (2006).

15. Didier D., Sergeyev S., Chimie nouvelle, 96 : 
92 (2007).

16. Didier D., Tylleman B., Lambert N., VandeVelde C. M. L., Blockhuys F., Collas A., Sergeyev S., Tetrahedron, 64: 6252 (2008).

17. Irving S., Vincent L., Ly P., Craig S. W., J. Org. Chem., 53: 98 (1988).

18. Mahon A. B., Craig D. C., Try A. C., Arkivoc,
12: 148 (2008).

19. Blum A. P., Ritter T., Grubbs R. H., Organometallics, 26: 2122 (2007).

20. Nyce G. W., Csihony S., Waymouth R. M., Hedrick J. L., Chem. Eur. J., 10: 4073 (2004). 